\title{
The role of the researcher as a producer and reviewer of scientific papers
}

\author{
Maria Helena Palucci Marziale
}

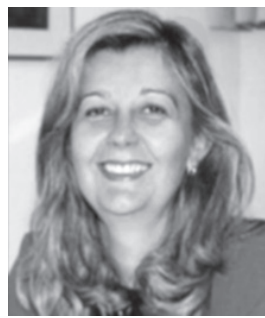

Based on the premise that producing research also means publishing it, any researcher should be prepared not only for research production, but also for dissemination and assessment.

Before being published in journals, scientific production goes through a judicious review process. Among the presented work, those studies are selected with original and innovative results that permit technical-scientific advances, also considering the purpose of the scientific journal, which is to publish duly proved and validated research results that are sufficiently important to guarantee publication costs.

Judicious and strict reviews should be left in charge of prepared, ethical, critical and reliable reviewers, who are able to perceive and acknowledge academic-scientific-technological merits. This process is called peer review $^{(1)}$, which scientific journals in different knowledge areas have used all around the world, as well as research funding agencies.

Despite controversies as to whether this is the most adequate process to assess papers, as it is considered slow and consultants do not receive any credit or acknowledgement for their work in most cases, the most prestigious journals in the scientific community still use it, as it has guaranteed the high quality of the papers published and represents an essential phase in the judgment process of scientific articles.

Most journals adopt double-blind reviews, where neither authors nor consultants are identified, but some use "open" reviews, in which the actors (author and consultant) are revealed.

Therefore, we believe it is paramount to prepare researchers to issue review opinions as well.

When issuing an opinion, the reviewer is expected to judge the quality of the research produced in his/ her knowledge domain, in the form of a scientific paper, and to follow criteria related to the contents and form of the presented text. The elements of merit are the originality and novelty contained in the study, the adequacy of theoretical-methodological frameworks and the knowledge advances resulting from the research. As for the form, the text should display clear writing, logical paragraph sequence, correct spelling and excellent translation, besides complying with journal standards.

It is underlined that the review should be critical, fair, impartial and confidential, and that the final decision to accept or reject the paper should be based on an objective assessment of the article's scientific and literary quality. Also, the opinion should mention the paper's contributions, strengths and weaknesses and whether it contributes or not to scientific advancement, a decisive indicator to accept or reject an article. 


\section{References}

1. Pinto AC, Andrade JB. Editorial. J. Braz. Chem. Soc. 2005;16:891.

Maria Helena Palucci Marziale is Chief Scientific Editor of the Latin American Journal of Nursing, Full Professor of the University of São Paulo at Ribeirão Preto College of Nursing, WHO Collaborating Centre for Nursing Research Development, Brazil, e-mail: marziale@eerp.usp.br. 